\title{
Cochlear Nerve Monitoring During Cerebellopontine Angle Operations
}

\author{
D.W. Rowed, J.M. Nedzelski, M.Z. Cashman, S. Stanton and R.V. Harrison
}

\begin{abstract}
The authors present their experience with intraoperative monitoring of cochlear nerve action potentials (AP) in 30 adult patients. Operative procedures were acoustic neuroma excision with attempted hearing preservation and selective vestibular neurectomy in patients with incapacitating Meniere's disease and serviceable hearing (SRT $<50 \mathrm{db}$, discrimination $>60 \%$ ). Loss of AP is detected rapidly and has been demonstrated after manipulation of the cochlear nerve and after coagulation of small arteries on the tumour capsule. Presence of an AP at the end of the procedure usually correlates with postoperative preservation of hearing. AP monitoring appears to be a reliable means of detecting potentially reversible changes in cochlear nerve function intraoperatively.
\end{abstract}

RÉSUMÉ: Surveillance du nerf cochléaire pendant la chirurgie de l'angle ponto-cérébelleux. Les auteurs décrivent leur expérience de la surveillance per-opératoire des potentiels d'action (PA) du nerf cochléaire chez 30 patients adultes. Ces patients subissaient une chirurgie pour l'excision d'un neurinome acoustique avec tentative de préservation de l'ouïe ou une neurectomie vestibulaire sélective en raison d'une maladie de Ménière invalidante (SRT $<50 \mathrm{db}$, discrimination $>60 \%$ ). La perte des PA est détectée rapidement et elle a été mise en évidence après la manipulation du nerf cochléaire et après la coagulation de petites artères sur la capsule tumorale. La présence d'un PA à la fin de l'intervention est habituellement en corrélation avec la préservation postopératoire de l'audition. La surveillance des PA semble être un moyen fiable de détecter peropératoire des changements potentiellement réversibles dans la fonction du nerf cochléaire.

Can. J. Neurol. Sci. 1988; 15:68-72

Posterior fossa operations, particularly in the region of the cerebellopontine angle, carry a risk of hearing loss. ${ }^{i-5}$ Electrophysiological monitoring of auditory function has recently been reported to be useful in preventing or lessening injury to the auditory nerve and cochlea. ${ }^{5,6}$ Brainstem auditory evoked potentials (BAEP) are the most frequently employed method of intraoperative monitoring, and have the potential advantage of reflecting both auditory nerve function and brainstem activity. ${ }^{7-11}$ Cochlear nerve compound action potentials (AP) have also been used to monitor auditory function intraoperatively, though less extensively than BAEP. ${ }^{6,12,13}$ The AP is reliable, and large in amplitude. It is easily displayed directly on the oscilloscope screen without summation or enhanced by only a few averages. Cochlear nerve function can therefore be studied in virtually real time. This is a potential advantage in detecting reversible changes in auditory function so that intraoperative perturbations of the nerve may be minimized. ${ }^{13}$ We present our experience with intraoperative cochlear AP monitoring in thirty adult patients who were undergoing either excision of a small acoustic neuroma by suboccipital craniectomy or retrolabyrinthine section of a vestibular nerve (RVN) for Meniere's disease.

\section{MeTHODS}

\section{Patients}

The study population consisted of 30 adult patients. Twelve patients were subjected to RVN and 18 had acoustic neuromas removed. RVN patients ranged in age from 21 to 56 years with a mean age of 41 years, and tumour patients were 27 to 62 years of age with a mean age of 48 years. There were 9 male tumour patients and 9 females and the vestibular neurectomy patients were 6 males and 6 females.

Anesthesia was induced with sodium thiopental and maintained with nitrous oxide, fentanyl citrate and low concentrations of isoflurane (less than one percent).

\section{Stimuli}

Click and tone pip stimuli were delivered to the ear ipsilateral to the operated cerebellopontine angle (CPA) via a receiver and a stock earmold which was taped securely into the external ear. A Nicolet $1007 \mathrm{~A}$ stimulus generator provided unfiltered clicks of $100 \mathrm{usec}$ duration and alternating polarity. A Nicolet 1002 tone generator provided the tone pips. For 2000,4000 , and 
$8000 \mathrm{~Hz}$ tone pips the rise/fall time and plateau was $1 \mathrm{msec}$. For the $1000 \mathrm{~Hz}$ tone pip the rise/fall time was $2 \mathrm{msec}$ and the plateau was $0 \mathrm{msec}$. The stimulus presentation rate was 11.2 per second for 200 or 500 sweeps.

\section{Recording}

Cochlear nerve APs were averaged by a Nicolet CA1000 computer. The response was amplified to a gain of $10{ }^{4}$ The high and low cut-off frequencies of the input bandpass filters were 30 and $1500 \mathrm{~Hz}$ with a $6 \mathrm{db} /$ octave rolloff. Recordings were made from the cochlear nerve and from the promontory of the middle ear. The promontory electrode was used more frequently because the cochlear nerve electrode tended to be moved easily during surgery. The recording electrode consisted of an insulated silver wire with a cotton wick tip. In the instance of tumour surgery, the promontory electrode was placed via a small myringotomy, whereas in vestibular neurectomy cases the electrode was positioned via the facial recess (Figure 1). Placing the promontory electrode in this fashion allowed monitoring of auditory function prior to exposure of the cerebellopontine angle and its contents. The reference electrode was placed on the frontal midline of the scalp just anterior to the hairline, and the ground electrode was placed on the contralateral shoulder. Either subcutaneous needles or silver-silver chloride surface electrodes were used.

Responses were displayed on an oscilloscope screen for immediate interpretation and recorded for storage by an $\mathrm{XY}$ plotter (Hewlett Packard 7035 B), or on magnetic disks (Nicolet DC 2000 disk controller). Latencies and amplitudes were obtained by visual cursor analysis using an oscilloscope.

\section{Intraoperative Monitoring Protocol}

Click thresholds were measured in $10 \mathrm{~dB}$ steps. Two hundred responses were averaged, and all thresholds were replicated.

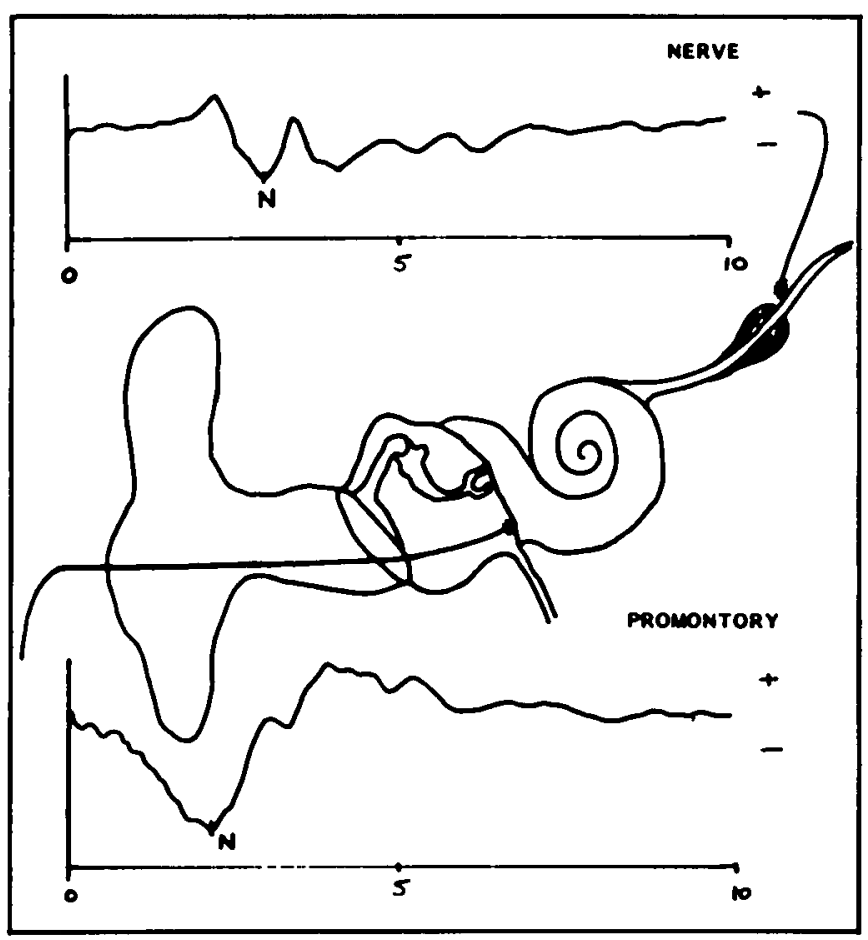

Figure 1 - Placement of cochlear nerve and promontory electrodes. Representative AP recordings from both sites.
Tone pip thresholds were measured at 1, 2, 4, and $8 \mathrm{KHz}$. As the operation proceeded, cochlear nerve function was monitored continuously using a stimulus intensity great enough to produce a clear AP (usually $20 \mathrm{~dB}$ above threshold). Changes were reported to the surgeons, in order to correlate AP alterations with manipulation of the cochlear nerve or surrounding structures, changes in the temperature of the irrigating solution, or other events in the operative field. Following tumour removal or vestibular nerve section, tone pip and click thresholds were recorded again. When time permitted, simultaneous promontory and direct nerve recordings were carried out.

\section{Preoperative and Postoperative Assessments}

Preoperative audiological assessment included audiometry with air, bone and speech reception thresholds (SRT), and speech discrimination testing. Brainstem auditory evoked potentials (BAEPs) were also recorded using 83 or $91 \mathrm{~dB}$ nHL clicks at a rate of 10.3 or $21.3 / \mathrm{sec} .{ }^{14}$ When the BAEP was abnormal, as it was in virtually all tumour patients, impedance testing and acoustic reflex thresholds and reflex decay measurements were made. Postoperatively audiometry was repeated. Intervals between preoperative and postoperative testing varied from 1 week to 6 months for tumour patients (mean $=1.3$ months), and from 2 weeks to 8 months for RVN patients (mean $=1.7$ months).

\section{Results}

\section{Reliability}

Intraoperative APs were obtained in 26 of 30 patients (87\%). The total includes 18 tumour patients with 3 failures and 12 RVN patients with 1 failure. A broken wire was identified retrospectively in one of the cases in whom APs could not be recorded, and in the other 3 cases the reasons for failure are not clear.

\section{Detection of Cochlear Nerve Dysfunction}

In a majority of patients the cochlear action potential did not change significantly during the course of the operative procedure.

The AP was present at the end of the operation in 9 of 15 acoustic neuroma patients and disappeared in 6 (Table 1). Thus the presence of an action potential at the conclusion of surgery was misleading in 2 patients (13\%) because only 7 of the 9 patients with APs had postoperative hearing. Postoperative hearing preservation or loss was accurately predicted in the remaining $13(87 \%)$. In vestibular neurectomy patients, the cochlear action potential remained present in all 11 at the conclusion of operation and all 11 had preservation of hearing (Table 1). Overall accuracy of prediction, therefore, was $24 / 26$ (92\%).

\section{Postoperative Hearing}

Quality of postoperative hearing, when preserved, was usually similar to preoperative hearing acuity (Figure 2). In the tumour patients, 6 of 7 patients with preserved hearing demonstrated SRT within $20 \mathrm{~dB}$ of preoperative level, and less than $30 \%$ decrease in speech discrimination. In one vestibular neurectomy patient SRT deteriorated by more than $20 \mathrm{~dB}$. The remaining RVN patients did not show worsening of SRT, and many had improved hearing postoperatively. One RVN patient 
Table 1: Correlation of Intraoperative Cochlear APs and Hearing Outcome $(\mathbf{N}=26)$

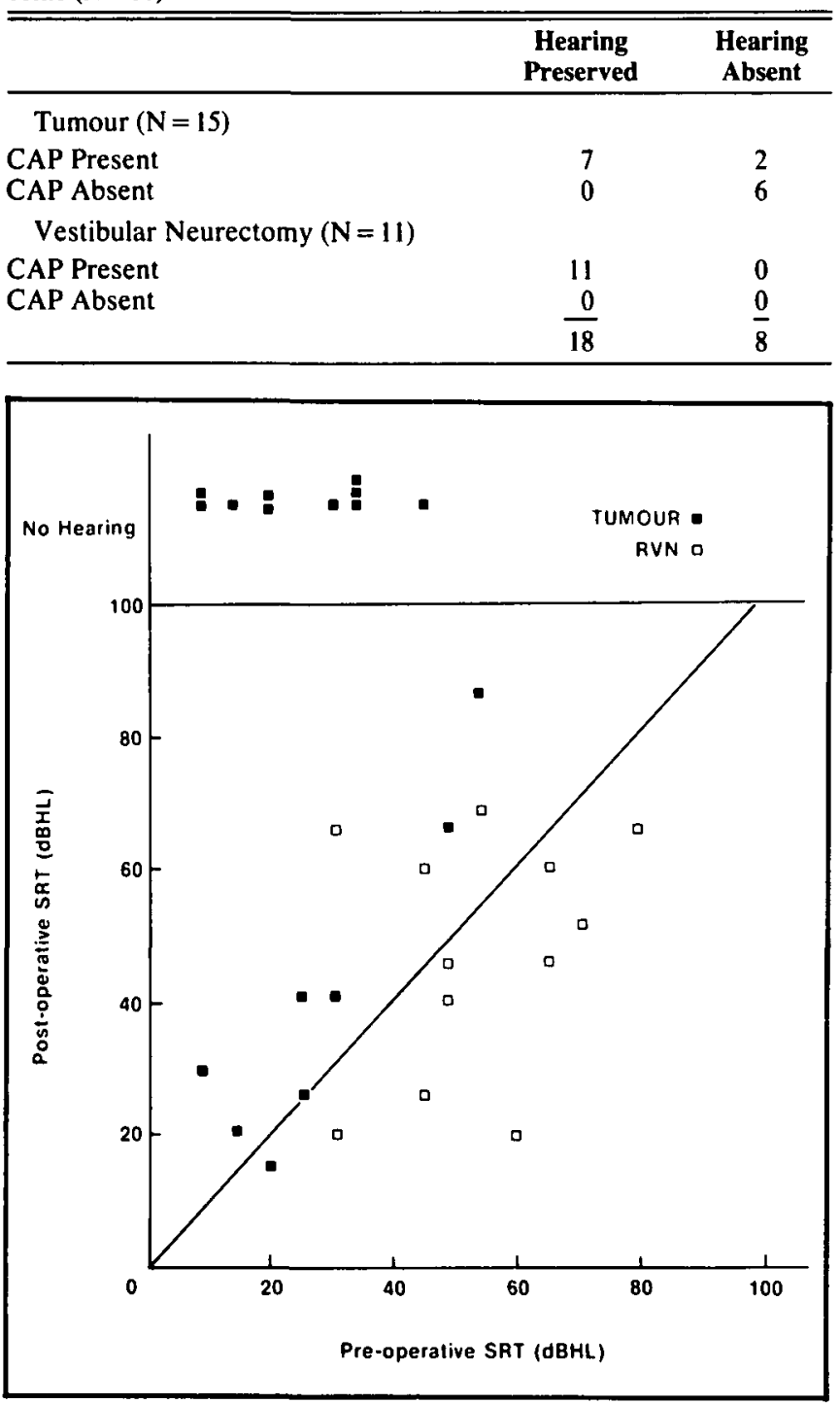

Figure 2 - Comparison of preoperative and postoperative SRT in acoustic neuroma and vestibular neurectomy patients $(N=30)$. Postoperative thresholds are similar to preoperative in most patients who had postoperative hearing preservation.

demonstrated a complete loss of the cochlear AP during surgery (Figure 3). Temporary cessation of the operation and bathing of the nerve with warmed irrigating solution was followed by return and gradual increase im amplitude of the AP. The patient's pre and postoperative audiograms were similar.

Since the inception of routine monitoring of these 2 patient groups in our institution we have failed to obtain intraoperative APs in 4 patients. Overall hearing preservation in the acoustic neuroma patients was $7 / 15(47 \%)$. Age and sex distribution of those tumour patients who had postoperative preservation of hearing was comparable to those who did not have postoperative hearing.

\section{Discussion}

We have been able to obtain reliable recordings of cochlear APs intraoperatively either from the promontory of the middle

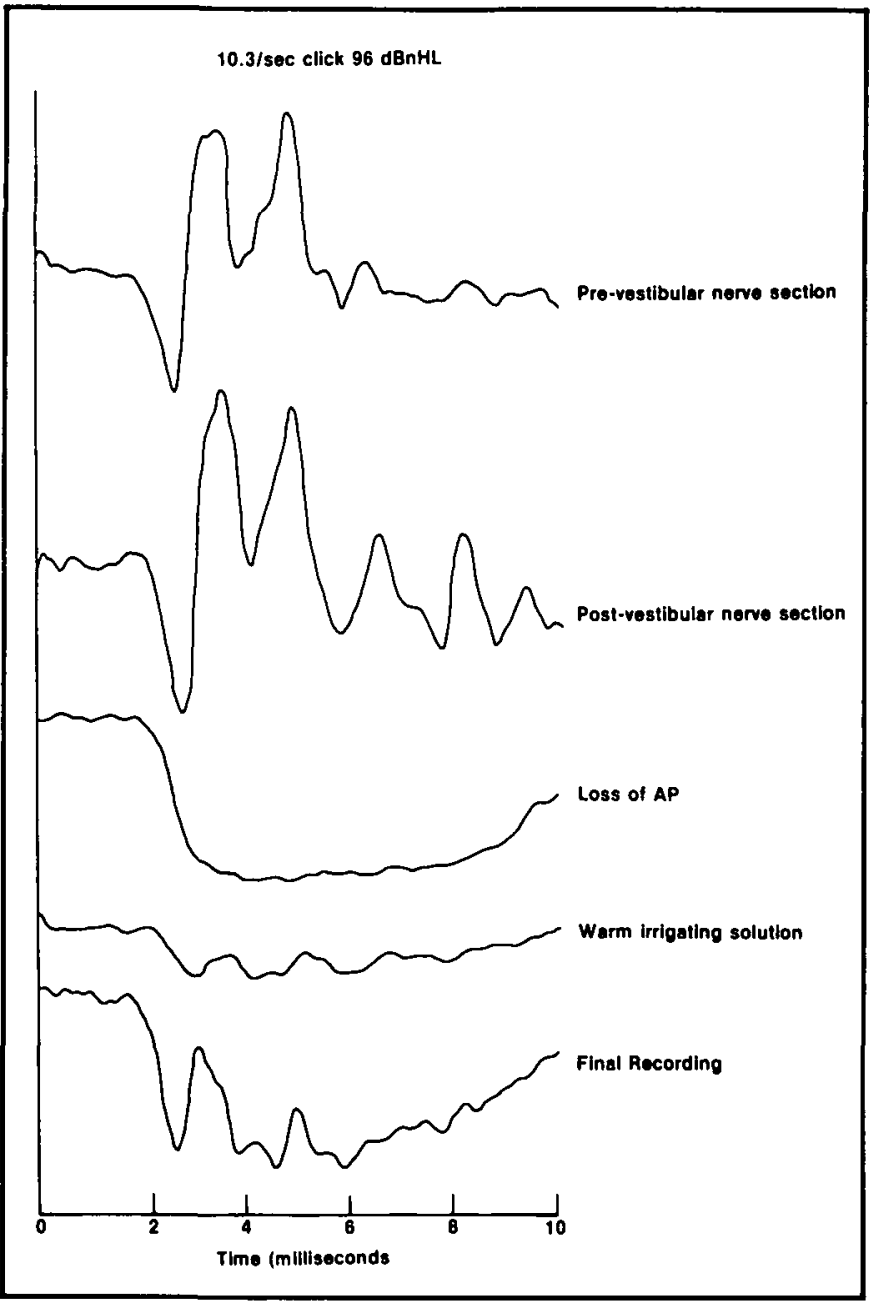

Figure 3 - Loss of AP after vestibular nerve section and its return with cessation of operation and warming.

ear or directly from the surface of the cochlear nerve. Responses are obtained in most patients (87\%). The AP, when it can be recorded, is consistent and easy to interpret, in contrast to BAEP, which may be subject to difficulties of interpretation, especially in tumour cases. ${ }^{9}$

Cochlear AP is relatively insensitive to anesthesia. ${ }^{15}$ In monitored patients we have nonetheless employed an anesthetic technique similar to that used for intraoperative monitoring of multimodality evoked potentials. The immediate availability of the AP is an apparent advantage. ${ }^{8,13,16}$ There is no delay because there is no need for a large number of responses to be averaged, and the response therefore can be examined immediately. This seems particularly useful in vestibular nerve sections where the isolation and division of the nerve is done in a very short period of time, and one wishes, therefore, to know immediately about any apparent deterioration in cochlear nerve function. In the one RVN patient in whom cochlear nerve manipulation caused temporary loss of the AP we were warned of the change immediately, ceased manipulating the nerve, and warmed it. ${ }^{15}$ The action potential returned and gradually increased in amplitude. Postoperative hearing showed slight deterioration, but was preserved. It is probable that our prompt action, aided by AP monitoring, prevented more severe hearing loss, though improvement in the AP may have been coincidental. 


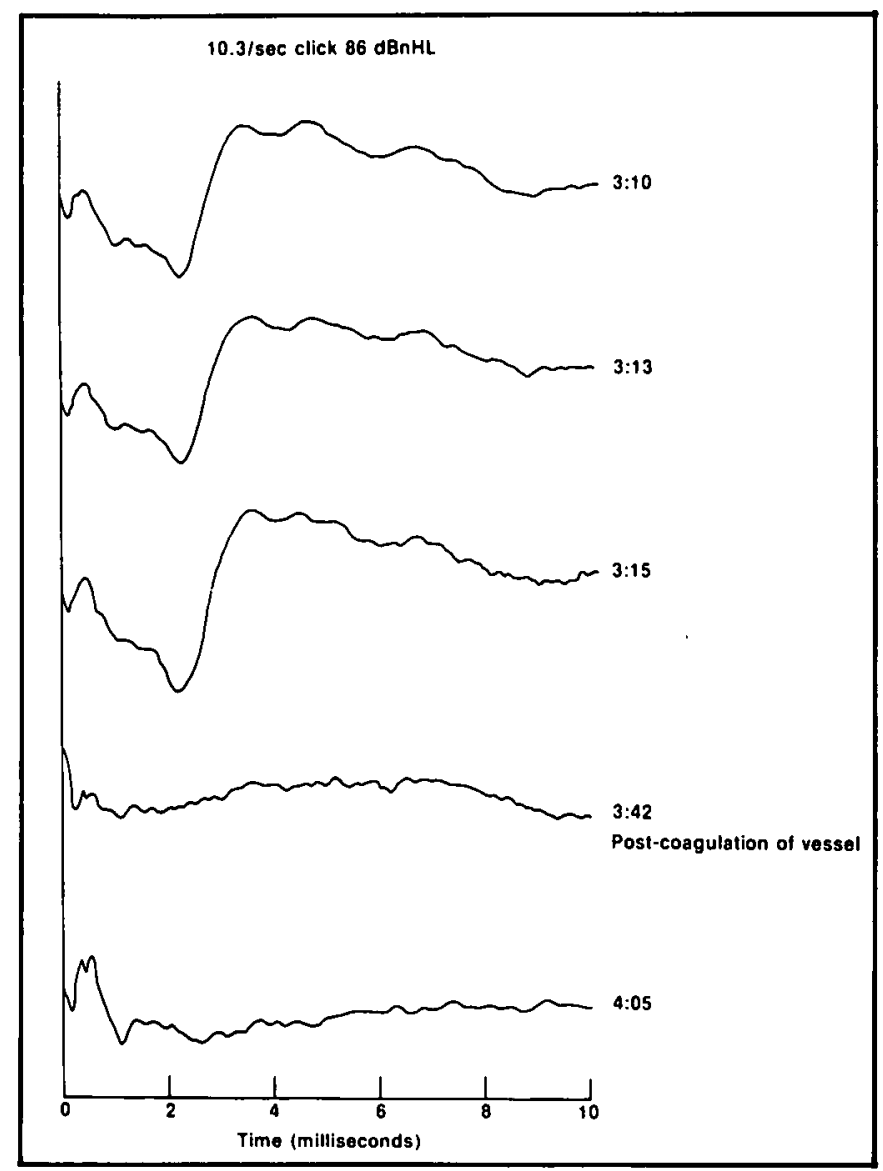

Figure 4 - Sudden loss of AP in an acoustic neuroma patient after coagulation of a small artery. The patient had no postoperative hearing.

Electrophysiological monitoring of facial nerve function has been indispensable to improved results in acoustic neuroma surgery. Cochlear nerve monitoring cannot yet be said to have a similar influence on suboccipital approach for acoustic neuroma excision with attempted hearing preservation. In one of the tumour patients, the AP disappeared at a time when there was no activity in the surgical field (Figure 4). Disappearance of the AP occurred soon after coagulation of a small arterial blood vessel, and ischemia of the nerve or the organ of Corti probably occurred. ${ }^{7}$ The AP did not return and there has been no return of hearing postoperatively. In retrospect, the 2 patients who had preservation of cochlear APs at the end of surgery and who subsequently had no hearing showed intraoperative indications that hearing deterioration had begun. One developed a very poor waveform and demonstrated the greatest threshold shift ( $45 \mathrm{~dB}$ ) of any of the patients who had AP preservation at the end of operation. The other patient showed no change in click threshold, but the $1000 \mathrm{~Hz}$ tone pip threshold increased dramatically near the end of operation (Figure 5). Preservation of hearing in half of the acoustic neuroma patients suggests that AP monitoring may be helpful. Until recently, hearing preservation after acoustic neuroma removal has been relatively infrequent. ${ }^{17}$ In patients with small tumours and good preoperative hearing in whom intraoperative monitoring of cochlear nerve function is employed, hearing preservation is now possible in about $50 \%$ of cases. ${ }^{13}$ Experience is limited, but the relatively high incidence of preservation of useful hearing may

\section{CLICK STIMULUS}

INITIAL THAESHOLO TEST

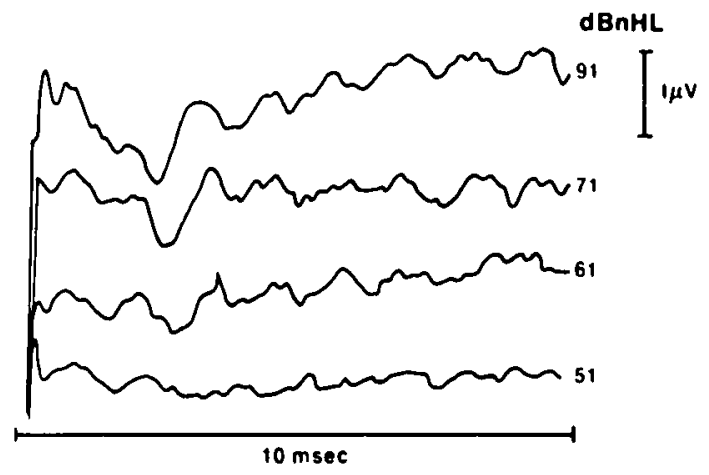

FINAL THRESHOLD TEST

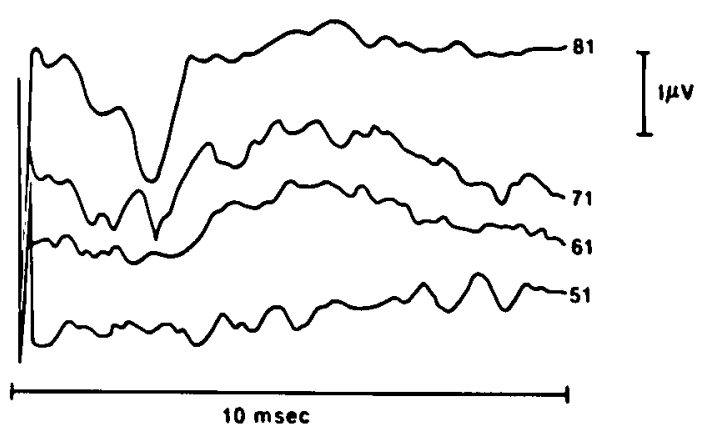

$1 \mathrm{KHz}$ STIMULUS

INITIAL THRESHOLD TEST

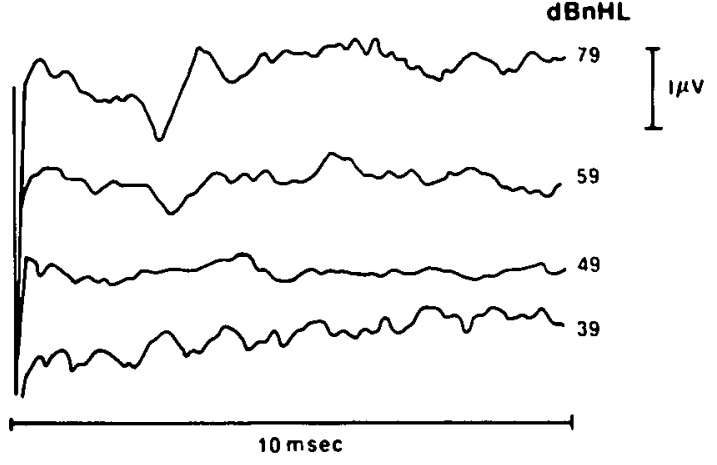

FINAL THAESHOLO TEST

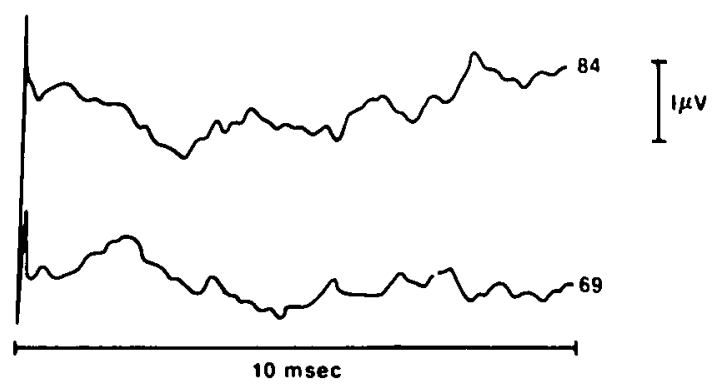

Figure 5 - Intraoperative thresholdrecordingsfor a patient with nopostoperative hearing. Note the dramatic increase in the $1 \mathrm{KHz}$ tone pip threshold with no change in click threshold. 
reflect sensitive detection of reversible cochlear and/or nerve dysfunction in at least some of these patients.

Both $B A E P^{8-11}$ and cochlear $\mathrm{AP}^{6,13}$ are potentially useful methods of monitoring auditory function intraoperatively. AP is more consistently detectable in our hands than is BAEP, particularly in tumour patients ${ }^{9}$ where wave I may be of low amplitude and wave $\mathrm{V}$ is frequently absent. AP is immediately available - either directly displayed on the oscilloscope screen or requiring only a few averages. The fact that changes can be seen almost in real time allows a more rapid response by the operating team and therefore a greater potential likelihood of minimizing injury to the nerve..$^{8,13}$

The fact that the AP is relatively insensitive to the influence of anesthesia is also an advantage. ${ }^{15}$ BAEP has the capability of detecting dysfunction in the centrally conducting pathways in the brainstem. This is potentially a useful property in larger cerebellopontine angle tumours, if an interpretable response can be obtained, but is not usually a concern in either RVN or in removal of small acoustic tumours with attempted hearing preservation. We believe that cochlear action potential monitoring is a useful means of continuously assessing cochlear function intraoperatively. The technique allows immediate feedback to the surgeon, which is of considerable value especially in brief operations like vestibular neurectomy where irreversible changes in auditory function may occur with extreme rapidity. Continuous monitoring may help to determine causes of intraoperative hearing loss and allows assessment of intraoperative maneuvers aimed at improving a deteriorating AP.

\section{REFERENCES}

1. Silverstein $\mathrm{H}$, Norrell $\mathrm{H}$. Retrolabyrinthine vestibular neurectomy. Otolaryngol Head Neck Surg 1982; 90: 778-782.

2. Silverstein $\mathbf{H}$, Norrell $H$. Retrolabyrinthine surgery: a direct approach to the cerebellopontine angle. Otolaryngol Head Neck Surg 1980; 88: 462-469.
3. Silverstein $\mathrm{H}$. Partial or total eighth nerve section in the treatment of vertigo. Otolaryngology 1978; 86: 47-60.

4. Brackmann DE, Hitselberger WE. Retrolabyrinthine approach: technique and newer indications. Laryngoscope 1978;88: 286-297.

5. Grundy BL, Lina A, Procopio PT, et al. Reversible evoked potential changes with retraction of the eighth cranial nerve. Anesth Analg 1981; 60: 835-838.

6. Moller AR, Janetta PJ. Monitoring auditory nerve potentials during operations in the cerebellopontine angle. Otolaryngol Head Neck Surg 1984; 92: 434-439.

7. Levine RA, Ojemann RG, Montgomery WW, et al. Monitoring auditory evoked potentials during acoustic neuroma surgery. Insights into the mechanism of hearing loss. Ann Otol Rhinol Laryngol 1984; 93: 116-23.

8. Abramson M, Stein BM, Pedley TA, et al. Intraoperative BAER monitoring and hearing preservation in the treatment of acoustic neuromas. Laryngoscope 1985; 95: 1318-22.

9. Zapulla R, Greenblatt E, Kaye S, et al. A quantitative assessment of the brainstem auditory evoked response during intraoperative monitoring. Neurosurgery 1984; 15: 186-91.

10. Ojemann RG, Levine RA, Montgomery WM, et al. Use of intraoperative auditory evoked potentials to preserve hearing in unilateral acoustic neuroma removal. J Neurosurg 1984; 61: 938-948.

11. Hardy RW Jr, Kinney SE, Lueders H, et al. Preservation of cochlear nerve function with the aid of brainstem auditory evoked potentials. Neurosurgery 1982; 11: 16-19.

12. Moller AR, Janetta PJ, Moller MB. Intracranially recorded auditory nerve response in man. Arch Otolaryngol 1982; 108: 77-82.

13. Silverstein $H$, McDaniel AB, Norrell H. Hearing preservation after acoustic neuroma surgery using intraoperative direct eighth cranial nerve monitoring. Am J Otol 1985; Suppl: 99-106.

14. Cashman MZ, Rossman MS, Nedzelski JM. Cerebellopontine angle lesions: an audiological test protocol. J Otolaryngol 1983; 12: 180-186.

15. Brown MC, Smith DI, Nuttall AL. Anesthesia and surgical trauma: their influence on the guinea pig compound action potential. Hear Res 1983; 10: 345-358.

16. Sekiya T, Iwabuchi T, Kamata S, et al. Deterioration of auditory evoked potentials during cerebellopontine angle manipulations. J Neurosurg 1985; 63: 598-607.

17. Jannetta PJ, Moller AR, Moller MB, et al. Technique of hearing preservation in small acoustic neuromas. Ann Surg 1984; 200: 513-23. 